\title{
ELECTRON DENSITY IN THE F1 LAYER OVER NORILSK IN 2007-2014
}

\author{
G.P. Kushnarenko \\ Institute of Solar-Terrestrial Physics SB RAS, \\ Irkutsk, Russia, kusch@iszf.irk.ru
}

\section{O.E. Yakovleva}

Institute of Solar-Terrestrial Physics SB RAS, Irkutsk, Russia, yakovleva@iszf.irk.ru

\author{
G.M. Kuznetsova \\ Institute of Solar-Terrestrial Physics SB RAS, \\ Irkutsk,Russia,kuz@iszf.irk.ru
}

\begin{abstract}
We report the results of the analysis of annual variations in daily electron density $(N)$ for various solar activity conditions - minimum, rise, and maximum (2007-2014) — obtained from digisonde measurements at the ionospheric station Norilsk $\left(69.4^{\circ}\right.$ $\left.\mathrm{N}, 88.1^{\circ} \mathrm{E}\right)$. New coefficients of the known semiempirical model (SEM) describing the connection between $N$ and thermosphere characteristics are calculated to identify regularities of these variations exactly at Norilsk station. The height changes of annual variations in the noon electron density $N$ are obtained in the F1region (120-200 km). The experimental data approximation describes $N$ quite satisfactorily at these heights
\end{abstract}

in the daytime of different seasons under different solar activity conditions. It is shown that in the years of solar minimum at all heights of the F1 layer the tendency remains for maximum $N$ in summer and for minimum $N$ in winter. In later years and in the year of maximum solar activity, a characteristic feature of the behavior of $N$ is the change in the phase of the annual variation by $180^{\circ}$ in the range of heights from 170 to $180 \mathrm{~km}$ : maximum $N$ is observed in winter; and minimum, in summer.

Keywords: annual variations, electron density, semi-empirical model.

valid within the frameworks of the atmospheric model NRLMSISE-00 [Picone et al., 2002] for respective neutral gas variations.

\section{MODEL CALCULATIONS}

At fixed F1-layer heights, $N$ can be described by the analytical relation [Shchepkin et al., 2008]

$$
\begin{aligned}
& N / N_{\mathrm{av}}=x_{1}+x_{2}\left([\mathrm{O}] /\left(5\left[\mathrm{O}_{2}\right]+\left[\mathrm{N}_{2}\right]\right)\right)^{1.5}+x_{3}\left([\mathrm{O}] /\left[\mathrm{N}_{2}\right]\right)^{0.5} \\
& \cos (\chi)^{0.5}+x_{4} \exp (-(T-600) / 600)+x_{5}\left(E / E_{0}\right) .
\end{aligned}
$$

Here $N_{\mathrm{av}}$ is the average value of $N$ over the entire data volume separately for each height; $x_{j}$ represents the coefficients of equation (1); $\chi$ is the solar zenith angle; $E_{0}$ is the ionizing radiation flux energy $E$ during sunspot maximum. Values of $E$ are calculated by the model [Tobiska, Eparvier, 1998]. Densities of neutral particles $[\mathrm{O}],\left[\mathrm{O}_{2}\right]$, and $\left[\mathrm{N}_{2}\right]$ and temperature $T$ are computed using the neutral atmosphere model NRLMSISE-00 [Picone et al., 2002]. To obtain the $x_{j}$ coefficients of equation (1), we take an array of daily hourly values of $N$ measured with the digisonde at heights of $120,130, \ldots, 190,200 \mathrm{~km}$ at Norilsk station in 2003-2014 from 7 to $18 \mathrm{LT}$. The thermosphere characteristics and $E$ values are calculated from both daily $F 10.7$ index values (in units of $10^{-22} \mathrm{~W} \mathrm{~m}^{-2} \mathrm{~Hz}^{-}$ ${ }^{1}$ ) and its values averaged over 81 day (three solar rotations). The geomagnetic activity level is taken into account using daily 3-hour values of $A_{\mathrm{p}}$ [http://wdc.kugi.kyoto-u.ac.jp]. Hence, we obtain coefficients of approximation equation (1) for minimum, rise, and maximum of solar activity, which contribute greatly to the current SEM version. Table 1 lists coefficients during solar minimum at Norilsk station. 
Table 1

Coefficients of approximation equation (1)

\begin{tabular}{|c|c|c|c|c|c|c|}
\hline$h, \mathrm{~km}$ & $N_{\mathrm{av}} \cdot 10^{4} \mathrm{~cm}^{-3}$ & $x_{1}$ & $x_{2}$ & $x_{3}$ & $x_{4}$ & $x_{5}$ \\
\hline 120 & 7.51 & -0.1844 & -7.403 & 4.842 & 0.0000 & 0.9708 \\
\hline 130 & 8.57 & -0.4140 & -7.960 & 5.459 & 0.2335 & 0.9473 \\
\hline 140 & 10.25 & -0.3128 & -8.238 & 5.310 & 0.2341 & 0.7888 \\
\hline 150 & 12.07 & -0.3352 & -7.917 & 5.106 & 0.4142 & 0.7005 \\
\hline 160 & 13.80 & -0.3521 & -7.048 & 4.688 & 0.5798 & 0.7009 \\
\hline 170 & 15.39 & -0.3646 & -5.463 & 4.130 & 0.7145 & 0.7496 \\
\hline 180 & 17.16 & -0.3462 & -2.644 & 3.430 & 0.7984 & 0.7455 \\
\hline 190 & 19.19 & -0.3267 & 1.388 & 2.659 & 0.8516 & 0.7008 \\
\hline 200 & 22.32 & -0.3604 & 5.298 & 1.983 & 0.9051 & 0.7580 \\
\hline
\end{tabular}

\section{RESULTS}

The typical curves of noon $N_{\text {cal }}$ annual variations at $150,180,190$, and $200 \mathrm{~km}$ for Norilsk station $\left(69.4^{\circ} \mathrm{N}\right.$, $\left.88.1^{\circ} \mathrm{E}\right)$, calculated for the period of interest (20072014), are shown in Figure 1. As an example, we have chosen the year of maximum solar activity - 2014. By comparison, experimental $N_{21}$ values are given for each height, i.e. $N_{\text {exp }}$ averaged over 21 days across the entire data set ( \pm 10 days centered at a given point). For all the heights there is sufficiently good agreement between the calculated and experimental curves of $N$ both in values and in shape.

At low heights $(150 \mathrm{~km})$, maximum $N_{\text {cal }}$ values are well-defined in summer; and minimum ones, in winter. Such a shape of $N(D)$ curves ( $D$ is the number of day in the year) is typical for heights $140-170 \mathrm{~km}$. At 190 and $200 \mathrm{~km}$, the maximum $N_{\text {cal }}$ values generally occur in winter; and minimum annual variations, in summer.

The $N(D)$ curves of one type are transformed into curves of another type near $180 \mathrm{~km}$. There is the lowest amplitude of annual variations at this height. The described changes in the shape of annual $N$ variations are caused by vertical variations in gas composition, which occur against a change in the electron density dependence of ionospheric charged particle neutralization rates.

Lack of data at all the heights at the end of the year $(D=300,330,360)$ is explained by the fact that in winter

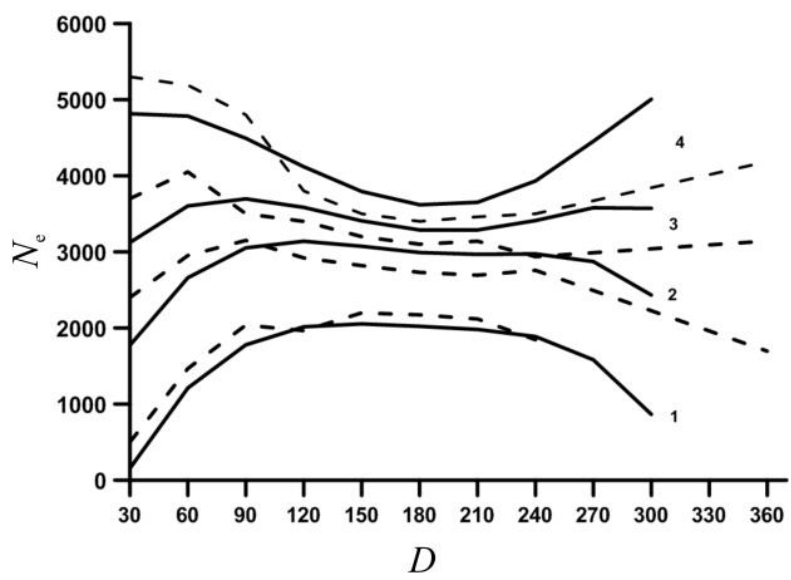

Figure 1. Annual variations in noon $N_{\text {cal }}$ values in 2014 at

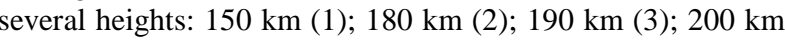
(4). The dashed line shows averaged experimental values of $N_{21}$. Along the $\mathrm{X}$-axis are days of the year in this height range the experimental values of $N$ are small and unreliable. Note also that the numerous gaps and absence of data in the studied $N$ arrays in these years in Norilsk lead to the fact that the correlation coefficients between the arrays of calculated and experimental values of $N$ for this period are within 0.94-0.70, with the highest value corresponding to the height of 120 $\mathrm{km}$; and the lowest, to the height of $200 \mathrm{~km}$. This results in a difference between $N_{\text {cal }}$ and $N_{21}$ at 190 and $200 \mathrm{~km}$.

We can observe some differences in the annual behavior of electron density in Norilsk during minimum solar activity: in general, according to SEM calculations, at all the heights the tendency remains for maximum $N$ in summer, which is confirmed by experimental values. In other years (2010-2014) of the period under study, the change of the $N(D)$ curves corresponds to the above behavior in 2014 .

Figure 2 shows the annual variations in noon $N_{\text {cal }}(D)$ calculated for 150, 180, and $200 \mathrm{~km}$ heights. For each height, $N_{\text {cal }}$ values correspond to three selected years: 2009 (minimum), 2012 (rise), and 2014 (maximum). Values for one specific height are shown in the Figure according to variations in $F 10.7$, which grew from 2010 to 2014 (Table 2). The $N_{\text {cal }}(D)$ curves for 2014 are at the

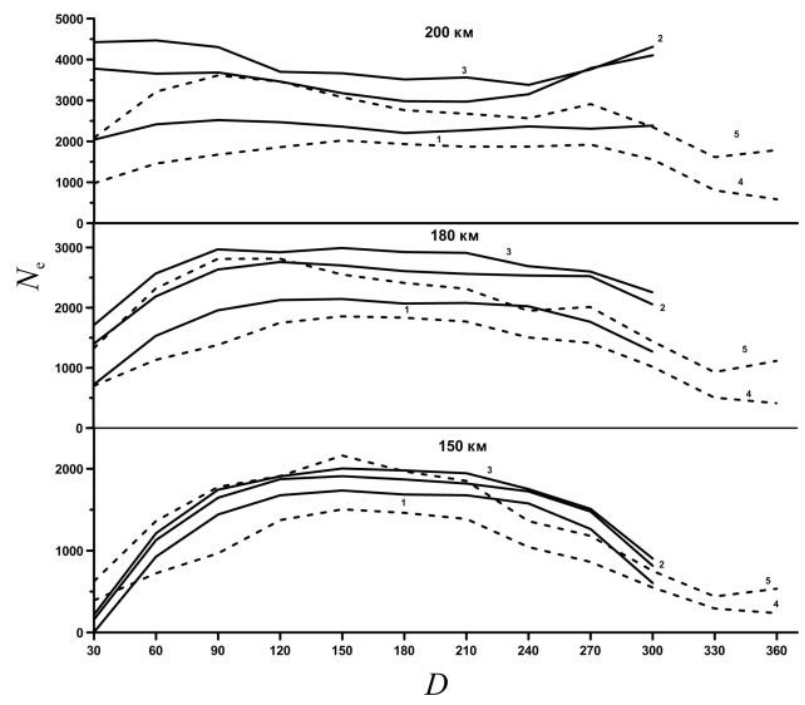

Figure 2. Annual variations in noon $N_{\text {cal }}$ at $150 \mathrm{~km}, 180$ $\mathrm{km}$, and $200 \mathrm{~km}$ for three years: 2009 (1), 2012 (2), 2014 (3). Dashed lines indicate the $N$ values obtained by the IRI model at each height for 2009 (4) and 2014 (5). Along the X-axis are days of the year 
top of the Figure; those for 2009, at the bottom.

Figure 2 also depicts the annual variations in noon $N$ for 2009 and 2014, which were calculated by the IRI model [Bilitza et al., 2017] for the above heights. The similarity with the calculated $N$ variations of interest lies in the fact that the summer maximum is observed at 150 $\mathrm{km}$ for all the years considered.

The difference between the $N$ variations calculated by IRI and those calculated by SEM is in the presence of two maxima in curves of annual variations at 180 and $200 \mathrm{~km}$ during equinoxes, with the spring maximum being much higher than the fall one. This shape of the IRI curves corresponds to all the years considered.

This is not observed for SEM curves of $N(D)$. The phase in the annual cycle of $N$ is reversed at $\sim 180 \mathrm{~km}$. This is confirmed by experimental values (see Figure 1). Our results differ from those obtained with IRI - the $N$ values calculated by IRI are lower almost for all the heights considered of the period under study.

In general, we can speak of a good approximation of most experimental material. As an example Table 3 shows calculated $N_{\text {cal }}$ and experimental monthly average $N_{\text {exp }}$ (daytime) values of electron density for April and June of the selected three years $(2007,2012$, and 2014) at two heights (150 and $190 \mathrm{~km}$ ). The data (see Table 3) show that the experimental values are quite reasonably consistent with the calculated values. At the same time, at $190 \mathrm{~km} N_{\text {cal }}$ differ from $N_{\text {exp }}$. Reasons of this difference have been discussed above.

Deviations $d N$ of monthly average $N_{\text {cal }}$, obtained by averaging daily values for each local hour, from experimental ones were computed from the formula

$$
d N=\left(N_{\text {cal }}-N_{\text {exp }}\right) / N_{\text {exp }} \text {. }
$$

Table 4 shows deviations $d N(\%)$ at 150 and $190 \mathrm{~km}$ in some months of 2007.

During forenoon hours, $N_{\text {cal }}$ exceed $N_{\text {exp }}$ at 150 and 190 $\mathrm{km}$ in all months; in the afternoon and in the evening, vice versa. A reason of this may be calculation errors at large $\left(>70^{\circ}\right)$ solar zenith angles for early morning and evening hours, as well as peculiarities of gas composition deviation from its model description [Shchepkin et al., 2008]. In particular, in winter the evening effect at high altitudes of the range under study may be due to the increased atomic oxygen density as compared to that adopted in the model.

Annual average $F 10.7$ in 2007-2015

\begin{tabular}{|c|c|c|c|c|c|c|c|c|c|}
\hline Year & 2007 & 2008 & 2009 & 2010 & 2011 & 2012 & 2013 & 2014 & 2015 \\
\hline$F 10.7$ & 74 & 69 & 71 & 80 & 113 & 120 & 123 & 146 & 118 \\
\hline
\end{tabular}

Table 2

Monthly average $N_{\text {exp }}$ and calculated $N_{\text {cal }}$ at 150 and $190 \mathrm{~km}\left(N \cdot 10^{4}, \mathrm{~cm}^{-3}\right)$ for local daytime hours

\begin{tabular}{|c|c|c|c|c|c|c|c|c|c|c|c|c|c|}
\hline \multirow{3}{*}{ year } & \multirow{3}{*}{ parameter } & \multicolumn{7}{|c|}{ April } & \multicolumn{5}{|c|}{ June } \\
\hline & & \multicolumn{12}{|c|}{$150 \mathrm{~km}$} \\
\hline & & $8 \mathrm{LT}$ & $10 \mathrm{LT}$ & $12 \mathrm{LT}$ & $14 \mathrm{LT}$ & $16 \mathrm{LT}$ & $18 \mathrm{LT}$ & $8 \mathrm{LT}$ & $10 \mathrm{LT}$ & $12 \mathrm{LT}$ & $14 \mathrm{LT}$ & $16 \mathrm{LT}$ & $18 \mathrm{LT}$ \\
\hline \multirow[t]{2}{*}{2007} & $N_{\mathrm{p}}$ & 12 & 15 & 16 & 15 & 12 & 10 & 14 & 16 & 18 & 17 & 15 & 12 \\
\hline & $N_{3}$ & 10 & 13 & 15 & 16 & 14 & 10 & 13 & 16 & 18 & 17 & 16 & 14 \\
\hline \multirow[t]{2}{*}{2012} & $N_{\mathrm{p}}$ & 13 & 16 & 18 & 17 & 14 & 10 & 15 & 18 & 19 & 18 & 16 & 13 \\
\hline & $N_{3}$ & 12 & 15 & 18 & 16 & 13 & 10 & 16 & 18 & 19 & 18 & 16 & 15 \\
\hline \multirow[t]{2}{*}{2014} & $N_{\mathrm{p}}$ & 14 & 17 & 19 & 18 & 15 & 10 & 16 & 19 & 20 & 19 & 17 & 14 \\
\hline & $N_{3}$ & 15 & 18 & 19 & 19 & 15 & 10 & 19 & 20 & 22 & 22 & 19 & 14 \\
\hline \multicolumn{14}{|c|}{$190 \mathrm{~km}$} \\
\hline \multirow[t]{2}{*}{2007} & $N_{\mathrm{p}}$ & 18 & 21 & 22 & 22 & 19 & 15 & 19 & 21 & 22 & 22 & 20 & 17 \\
\hline & $N_{3}$ & 15 & 18 & 20 & 22 & 21 & 18 & 18 & 20 & 22 & 21 & 20 & 20 \\
\hline \multirow[t]{2}{*}{2012} & $N_{\mathrm{p}}$ & 24 & 28 & 30 & 30 & 27 & 22 & 24 & 27 & 28 & 28 & 26 & 23 \\
\hline & $N_{3}$ & 20 & 25 & 28 & 27 & 25 & 17 & 24 & 26 & 28 & 27 & 28 & 22 \\
\hline \multirow[t]{2}{*}{2014} & $N_{\mathrm{p}}$ & 29 & 33 & 35 & 34 & 31 & 26 & 28 & 31 & 32 & 32 & 30 & 27 \\
\hline & $N_{3}$ & 23 & 27 & 29 & 29 & 26 & 20 & 26 & 27 & 29 & 28 & 27 & 24 \\
\hline
\end{tabular}

Table 4

$d N(\%)$ at 150 and $190 \mathrm{~km}$ in 2007

\begin{tabular}{|c|c|c|c|c|c|c|c|c|c|c|c|c|}
\hline \multicolumn{13}{|c|}{$150 \mathrm{~km}$} \\
\hline${ }_{\mathrm{LT}}^{\mathrm{montm}}$ & 7 & 8 & 9 & 10 & 11 & 12 & 13 & 14 & 15 & 16 & 17 & 18 \\
\hline February & - & - & - & - & 34 & 18 & -11 & -30 & -41 & - & - & - \\
\hline March & - & - & - & - & 34 & 24 & 20 & 7 & -4 & -25 & -33 & -50 \\
\hline April & - & 33 & 25 & 16 & 9 & 4 & 1 & -4 & -7 & -11 & -11 & -25 \\
\hline June & 18 & 9 & 7 & 2 & -2 & -5 & -1 & -2 & -3 & -7 & -12 & -12 \\
\hline September & - & - & - & 36 & 23 & 17 & 9 & 7 & 1 & 3 & -14 & -23 \\
\hline \multicolumn{13}{|c|}{$190 \mathrm{~km}$} \\
\hline February & - & - & - & - & 11 & -6 & -20 & -31 & -33 & -36 & 13 & - \\
\hline March & - & - & - & 25 & 9 & - & -5 & -14 & -17 & -29 & -29 & -22 \\
\hline April & 30 & 18 & 17 & 16 & 12 & 8 & 4 & -3 & -8 & -12 & -14 & -19 \\
\hline June & 11 & 9 & 8 & 7 & 5 & 2 & 2 & 2 & 1 & -3 & -7 & -11 \\
\hline September & - & 45 & 21 & 17 & 13 & 4 & -1 & -7 & -7 & -10 & -20 & -21 \\
\hline
\end{tabular}




\section{CONCLUSION}

The use of the semi-empirical model describing the relationship between electron density and thermosphere characteristics, solar zenith angle, and ionizing radiation flux intensity allowed a detailed analysis of the behavior of the ionosphere below $200 \mathrm{~km}$ under different solar activity conditions.

The obtained coefficients of the SEM regression equation for Norilsk station are consistent with specific conditions of minimum, maximum, and rise of solar activity at Norilsk station and are important complements to the model.

The approximation of the $N$ array allowed us to examine the annual electron density variations at Norilsk station for the period from 2007 to 2014 . We have shown that during years of minimum solar activity at all F1-layer heights, the tendency remains for maximum values of $N$ in summer; and for minimum ones, in winter. In subsequent years and in the year of maximum solar activity, a characteristic feature of the $N$ behavior is the change in the phase of the annual variation by $180^{\circ}$ in the height range of 170 to $180 \mathrm{~km}$ : maximum values are observed in winter; and minimum, in summer.

Further collection of experimental data will allow us to develop a more complete version of SEM for different geoheliophysical conditions. This model is important, in particular, for evaluation of gas composition of the thermosphere from ionospheric measurements.

The work was performed with budgetary funding of Basic Research program II.16.1.1. «Research into the influence of solar activity and processes in the lower atmosphere on thermodynamic characteristics of the atmosphere, World Ocean, and climate.» The results were obtained using the equipment of Center for Common Use «Angara» [http://ckp-rf.ru/ckp/3056].

\section{REFERENCES}

Bilitza D., Altadill D., Truhlik V., Shubin V., Galkin I., Reinisch B., Huang X. International Reference Ionosphere 2016: From ionospheric climate to real-time weather predictions. Space Weather. 2017, vol. 15, pp. 418-429. DOI: 10.1002/ 2016SW001593.

Picone J.M., Hedin A.E., Drob D.P., Aikin A.C. (GTD72000) NRLMSIS-00 Empirical model of the atmosphere; statistical comparisons and scientific issues. J. Geophys. Res. 2002, vol. 107, no. A12, p. 1469. DOI: 10.1029/2002JA009430.

Shchepkin L.A., Kushnarenko G.P., Freizon I.A., Kuznetsova G.M. The electron density connection with the thermospheric state in the middle ionosphere. Geomagnetizm $i$ aeronomiya [Geomagnetism and Aeronomy].1997, vol. 37, no. 5, pp. 106-113. (In Russian).

Shchepkin L.A., Kushnarenko G.P., Kuznetsova G.M. Annual variation of the electron density in the ionosphere F1 region. Solnechno-zemnaya fizika [Solar-Terrestrial Physics]. 2005, iss. 7, pp. 62-67. (In Russian).

Shchepkin L.A., Kuznetsova G.M., Kushnarenko G.P., Ratovsky K.G. The interpretation of the electron density measurements with the semiempirical model help. Solnechnozemnaya fizika [Solar-Terrestrial Physics]. 2007, iss. 10, pp. 89-92. (In Russian).

Shchepkin L.A., Kuznetsova G.M., Kushnarenko G.P., Ratovsky K.G. Approximation of data on measurements of electron concentration in the middle ionosphere at low solar activity. Solnechno-zemnaya fizika [Solar-Terrestrial Physics]. 2008, no. 11, pp. 66-69. (In Russian).

Tobiska W.K., Eparvier F.G. EUV97: Improvements to EUV irradiance modeling in the soft X-rays and EUV. Solar Phys. 1998, vol. 147, no. 1. pp. 147-159. DOI: 10.1023/A: 1004931416167.

URL: http://wdc.kugi.kyoto-u.ac.jp (accessed September 26, 2018). 2018).

URL: http://ckp-rf.ru/ckp/3056 (accessed September 26,

How to cite this article

Kushnarenko G.P., Yakovleva O.E., Kuznetsova G.M. Electron density in the F1 layer over Norilsk in 2007-2014. Solar-Terrestrial Physics. 2019. Vol. 5, Iss. 2. P. 109-112. DOI: 10.12737/stp52201915. 